\title{
Determinants of Decision to Delivery Interval (DDI) in Emergency Caesarean Sections in Ladoke Akintola University of Technology Teaching Hospital Ogbomoso, Nigeria
}

Owonikoko KM ${ }^{*}$, Olabinjo AO, Bello-Ajao HT, Adeniran MA and Ajibola TA

Department of Obstetrics and Gynecology, Ladoke Akintola University of Technology Teaching Hospital, Ogbomoso, Oyo State, Nigeria

"Corresponding author: Owonikoko KM, Department of Obstetrics and Gynecology, Ladoke Akintola University of Technology Teaching Hospital, Ogbomoso, Oyo State, Nigeria, E-mail: musliudin@yahoo.co.uk

Received date: May 07, 2018; Accepted date: May 21, 2018; Published date: May 28, 2018

Copyright: @2018 Owonikoko KM, et al. This is an open-access article distributed under the terms of the Creative Commons Attribution License, which permits unrestricted use, distribution, and reproduction in any medium, provided the original author and source are credited.

\begin{abstract}
Background: Emergency caesarean sections are invaluable when vaginal delivery is either impossible or possess risk to the life of mother and or the foetus. Patients however still encounter delays after the decision has been made, despite recommended time frame.

Objective: This is to identify the common indications for emergency caesarean section, factors responsible for delays after decision has been made and the short-term effect on the mother and neonate.

Materials and methods: This was a retrospective study in which case records of patients who had emergency caesarean section were retrieved. Information about sociodemographic characteristics, booking status, parity, indication for surgery, decision time, incision time and short term feto-maternal outcomes were collected with the aid of structured proforma. Data was analyzed with Stata: Release 13 statistical software.

Results: The mean age of participants was $28.9 \pm 5.1$ years, $51.3 \%$ were booked, primary caesarean section rate was $84.0 \%$. The commonest indication was cephalo-pelvic disproportion (40.5\%). The mean DDI was $145.3 \pm$ $69.2 \mathrm{~min}$. Patients' factor was the leading cause of delay due to lack of funds and non-provision of surgical materials $(53.5 \%)$. Leading hospital factors were non-availability of blood and blood products (32.8\%) and power outage (28.0\%). Five min APGAR score was normal in $92.3 \%$ of the neonates and $0.5 \%$ had severe asphyxia.

Conclusion: This study shows that there are still avoidable delays in emergency caesarean section. Although there were no immediate neonatal complications, improving health care delivery so as to eliminate the identified causes would go a long way in reducing these delays.
\end{abstract}

Keywords: Emergency; Caesarean; Surgical

\section{Introduction}

Caesarean section is a deliberate surgical incision made on the uterus through an anterior abdominal wall incision with the aim of delivering the product of conception after the age of viability [1]. It is indicated when vaginal delivery is either impossible or the risks of vaginal delivery outweighs the benefit to either the mother, her foetus or both $[1,2]$.

According to timing of caesarean section, a four step classification system has been adopted by the RCOG namely: emergency, urgent, scheduled and elective [2-5].

The decision to delivery interval can be defined as the interval in minutes from the date and time of decision to carry out caesarean section to the date and time of delivery of the baby [4-6]. The RCOG recommends a delivery within $30 \mathrm{~min}$ for emergency caesarean deliveries and a maximum of $75 \mathrm{~min}$ for urgent caesarean deliveries $[4,7]$. In order to be valuable as audit standard, these targets need to be evidence based and achievable.
Though the feasibility, justification and benefits of these time frames have been questioned [2,4] studies have demonstrated that for both emergency and urgent caesarean sections, maternal and perinatal outcomes deteriorate measurably when the decision to delivery interval exceeds $75 \mathrm{~min}[4,8]$. It is therefore important to ensure delivery within a short time frame in order to achieve preservation of maternal and foetal life in the most urgent situations $[8,9]$.

The procedure of caesarean section is complex and multidisciplinary, involving the Anaesthesiologist and his trained assistant, the Obstetrician and his assistant, a theatre Nurse and a Neonatologist. These staff must be assembled, some of them must review patient and also prepare her. Some patients would need extra attention and stabilization to ensure that her condition is optimal before the surgery can be done. Failure to stabilize patient may increase the risk of maternal mortality and morbidity as a result of the surgery or complications of anaesthesia [7-9].

Keeping with the recommended time frame is difficult especially in government owned hospitals where the cost of healthcare is born by patients. Lack of money may lead to delay in accessing care. Other factors that have been identified in previous studies include; lack of coordination between the health team involved, increase patient load 
Citation: Owonikoko KM, Olabinjo AO, Bello-Ajao HT, Adeniran MA, Ajibola TA (2018) Determinants of Decision to Delivery Interval (DDI) in Emergency Caesarean Sections in Ladoke Akintola University of Technology Teaching Hospital Ogbomoso, Nigeria. Clinics Mother Child Health 15: 294. doi:10.4172/2090-7214.1000294

Page 2 of 5

with resultant long waiting list for surgery, delay in cross matching blood and stabilizing unfit patients, delay due to malfunctioning apparatus shortage of instruments, absence of sutures drapes and theatre technical staff, power outage and limited number of operating theatres $[3,4,7]$. The aim of this study is to explore the factors that cause delay in delivery after a decision have been made for an emergency caesarean section and effect of such delays on the shortterm outcome on the mother and her new born baby.

\section{Materials and Methods}

The study was conducted at the LAUTECH Teaching Hospital, Ogbomoso, located in Oyo State of Nigeria. It was a cross-sectional hospital based retrospective study. Subjects were patients who had emergency caesarean section between January 2013 and December 2014. Their records were retrieved and analyzed. The records of all cases of emergency caesarean sections performed in LTH, Ogbomoso between 1st of January 2013 and $31^{\text {st }}$ of December 2014 were retrieved. Information was extracted with the aid of a proforma. The information included sociodemographic parameters of the patients, indications for surgery, decision-delivery interval and feto-maternal outcome. Only pregnancies between 37-42 weeks were included in the study to avoid bias from complications resulting from gestational age and cases of intrauterine fetal death diagnosed before surgery were excluded. The approval for the study was obtained from ethical review committee of LTH Ogbomoso.

Microsoft excel was used for data entry and the Stata: Release 13 Statistical Software. College Station, TX: Stata Corp LP was used for analysis. Frequency distribution tables were generated. The Chi-square and student t-tests were used to determine relationship between variables where each was applicable and the level of significance was set at P-values of $<0.05$, at confidence interval of $95 \%$ for inferential statistics.

\section{Results}

Between $1^{\text {st }}$ of January 2013 and $31^{\text {st }}$ of December 2014, a total of 294 Caesarean sections were performed and 246 (83.7\%) were emergency caesarean sections out of which 232 (94.3\%) patients fulfilled the criteria for the study. The mean age was $28.9 \pm 5.1$ years. Majority of the patients were married 207 (89.2\%) Yoruba 222 (95.7\%) women (Table 1).

\begin{tabular}{|c|c|c|}
\hline \multicolumn{3}{|c|}{ Population } \\
\hline Variable & Number (232) & Percentage \\
\hline \multicolumn{3}{|l|}{ Age } \\
\hline $15-19$ & 4 & 1.7 \\
\hline $20-24$ & 35 & 15.1 \\
\hline $25-29$ & 95 & 41 \\
\hline $30-34$ & 73 & 31.5 \\
\hline $35-39$ & 13 & 5.6 \\
\hline$>40$ & 12 & 5.2 \\
\hline \multicolumn{3}{|c|}{ Marital Status } \\
\hline Married & 207 & 89.2 \\
\hline
\end{tabular}

\begin{tabular}{|c|c|c|}
\hline Single & 24 & 10.4 \\
\hline Cohabiting & 1 & 0.4 \\
\hline \multicolumn{3}{|l|}{ Ethnicity } \\
\hline Yoruba & 222 & 95.5 \\
\hline Igbo & 6 & 2.6 \\
\hline Hausa & 2 & 0.9 \\
\hline Others & 2 & 0.9 \\
\hline \multicolumn{3}{|l|}{ Religion } \\
\hline Christianity & 177 & 76.3 \\
\hline Islam & 55 & 23.7 \\
\hline \multicolumn{3}{|l|}{ Occupation } \\
\hline Unskilled & 140 & 60.3 \\
\hline Professional & 55 & 23.7 \\
\hline Skilled & 37 & 16 \\
\hline
\end{tabular}

Table 1: Sociodemographic characteristics of study.

More than half 119 (51.3\%) of the study population were booked and $53.0 \%$ were nulliparous. Only $37(16.0 \%)$ had a previous $\mathrm{C} / \mathrm{S}$ putting the primary $\mathrm{C} / \mathrm{S}$ rate at $84.0 \%$. Twenty-eight $(75.7 \%)$ of those who had repeat $\mathrm{C} / \mathrm{S}$ had 1 previous caesarean delivery, 7 (18.9\%) had 2 previous $\mathrm{C} / \mathrm{S}$ and $2(5.4 \%)$ had 3 (Table 2).

\begin{tabular}{|c|c|c|}
\hline Variable & Number (232) & Percentage \\
\hline \multicolumn{3}{|l|}{ Booking Status } \\
\hline Booked & 119 & 51.3 \\
\hline Unbooked & 113 & 48.7 \\
\hline \multicolumn{3}{|l|}{ Parity } \\
\hline Nulliparous & 123 & 53 \\
\hline Primiparous & 57 & 24.6 \\
\hline Multiparous & 43 & 18.5 \\
\hline Grand multiparous & 9 & 3.9 \\
\hline \multicolumn{3}{|c|}{ Number Of Previous Caesarean Deliveries (N=37 [16\%]) } \\
\hline 1 & 28 & 75.7 \\
\hline 2 & 7 & 18.9 \\
\hline 3 & 2 & 5.4 \\
\hline
\end{tabular}

Table 2: Obstetric status of study population.

Table 3 shows that the commonest indication for caesarean delivery was cephalopelvic disproportion 94 (40.5\%) and cord prolapse had the shortest mean decision incision interval $(87.6 \pm 50.6) \mathrm{min}$. One hundred and forty-nine (64.2\%) of the surgeries were done during the day and 83 (35.8\%) were done in the night. The mean DDI for daytime 
Citation: Owonikoko KM, Olabinjo AO, Bello-Ajao HT, Adeniran MA, Ajibola TA (2018) Determinants of Decision to Delivery Interval (DDI) in Emergency Caesarean Sections in Ladoke Akintola University of Technology Teaching Hospital Ogbomoso, Nigeria. Clinics Mother Child Health 15: 294. doi:10.4172/2090-7214.1000294

Page 3 of 5

surgeries was $152.2 \pm 69.5$ and that of night surgeries was $133.0 \pm 67.2$ $\min$.

\begin{tabular}{|c|c|c|}
\hline \multicolumn{3}{|l|}{ Delivery interval } \\
\hline Variable & Number (\%) & Mean DDI (min) \\
\hline \multicolumn{3}{|l|}{ Indications for caesarean section } \\
\hline Cephalopelvic disproportion in labor & $94(40.5)$ & $145.8 \pm 63.8$ \\
\hline Suspected foetal distress & $54(23.3)$ & $145.4 \pm 82.1$ \\
\hline Failed VBAC* & $30(12.9)$ & $153.2 \pm 88.3$ \\
\hline Failed induction & $18(7.8)$ & $139.1 \pm 48.3$ \\
\hline Severe pre-eclampsia+unfavourable cervix & $13(5.6)$ & $128.5 \pm 49.4$ \\
\hline Antepartum haemorrhage & $11(4.7)$ & $126.6 \pm 46.0$ \\
\hline Breech presentation in labour & $7(3.0)$ & $205.3 \pm 26.8$ \\
\hline Cord prolapse & $4(1.7)$ & $87.6 \pm 50.6$ \\
\hline Retained 2nd twin & $1(0.4)$ & 130 \\
\hline
\end{tabular}

Table 3: Indication for caesarean section.

Only $2(0.9 \%)$ of the surgeries were done within 30 minutes and 19 (8.2\%) were done within an hour (Table 4$)$.

Non-availability of blood and blood products was responsible in 76 $(32.8 \%)$ and delay in signing consent form was the reason in 70 $(30.2 \%)$ of the patients (Table 5).

\begin{tabular}{|l|l|}
\hline DDI (mins) & Number (\%) \\
\hline$\leq 30$ & $2(0.9)$ \\
\hline $31-60$ & $17(7.3)$ \\
\hline $61-90$ & $45(19.4)$ \\
\hline $91-120$ & $49(21.1)$ \\
\hline $121-150$ & $18(7.8)$ \\
\hline $151-180$ & $42(18.1)$ \\
\hline $181-210$ & $23(9.9)$ \\
\hline$\geq 210$ & $36(15.5)$ \\
\hline
\end{tabular}

Table 4: Decision-delivery interval (DDI).

\begin{tabular}{|l|l|l|}
\hline Factors & Number & Percentage \\
\hline Patient factors & 12 & 5.2 \\
\hline Need to stabilize mother & 124 & 53.5 \\
\hline $\begin{array}{l}\text { Lack of funds and non-provision of surgical } \\
\text { materials }\end{array}$ & 70 & 30.2 \\
\hline Delay in signing consent & & \\
\hline Hospital factors & & \\
\hline
\end{tabular}

\begin{tabular}{|l|l|l|}
\hline Power outage & 65 & 28 \\
\hline Non-availability of blood and blood products & 76 & 32.8 \\
\hline Shortage of theatre staff & 3 & 1.3 \\
\hline Shortage of operating theatre & 10 & 4.3 \\
\hline Delay in administration of anaesthesia & 35 & 15.1 \\
\hline
\end{tabular}

Table 5: Factors responsible for delay.

\begin{tabular}{|c|c|c|}
\hline Variable & Number & Percentage \\
\hline \multicolumn{3}{|l|}{ Maternal outcome } \\
\hline Postpartum haemorrhage & 21 & 9.1 \\
\hline Postpartum blood transfusion & 24 & 10.3 \\
\hline Need for ICU admission* & 1 & 0.4 \\
\hline Puerperial sepsis & 10 & 4.3 \\
\hline \multicolumn{3}{|l|}{ Fetal outcome } \\
\hline Fresh still birth & 11 & 4.7 \\
\hline \multicolumn{3}{|l|}{5 Minute APGAR Score $(n=221)$} \\
\hline$\geq 7$ & 206 & 93.2 \\
\hline 6 & 5 & 2.3 \\
\hline $4-5$ & 9 & 4.1 \\
\hline$<3$ & 1 & 0.5 \\
\hline SCBU admission ${ }^{* *}$ & 46 & 20.8 \\
\hline Neonatal death & 1 & 0.5 \\
\hline
\end{tabular}

Table 6: Outcome of caesarean deliveries.

\begin{tabular}{|c|c|c|c|c|}
\hline DDI (min) & $\leq \mathbf{3 0}$ & $31-75$ & $>75$ & P-value \\
\hline \multicolumn{5}{|c|}{5 min APGAR score } \\
\hline$\geq 7$ & 2 & 26 & 178 & \\
\hline 6 & 0 & 0 & 5 & 0.11 \\
\hline $4-5$ & 0 & 6 & 3 & \\
\hline$\leq 3$ & 0 & 0 & 1 & \\
\hline \multicolumn{5}{|c|}{ SCBU admission } \\
\hline Yes & 0 & 11 & 35 & 0.89 \\
\hline No & 2 & 21 & 152 & \\
\hline \multicolumn{5}{|c|}{ Perinatal mortality } \\
\hline Yes & 0 & 6 & 6 & 0.59 \\
\hline No & 2 & 32 & 186 & \\
\hline
\end{tabular}

Table 7: Analysis of DDI and perinatal outcome. 
Feto-maternal outcome was assessed and 21 (9.1\%) had postpartum haemorrhage, $24(10.3 \%)$ were transfused post operatively, $1(0.4 \%)$ required ICU admission, 10 (4.3\%) had puerperal sepsis. More than half of the study population had a normal postpartum PCV, less than one-third had mild anaemia and $27(11.6 \%)$ had moderate anaemia. Eleven foetuses were delivered as stillborn and a case of neonatal death was recorded, 12 perinatal mortalities therefore occurred with a perinatal mortality rate of $5.2 \%$. Five minute APGAR score was normal in $206(93.2 \%)$ of neonates, mild asphyxia was noted in $5(2.3 \%)$, moderate asphyxia in $9(4.1 \%)$ and $1(0.5 \%)$ was severely asphyxiated. Forty-six (20.8\%) of the neonates were admitted in the SCBU (Table 6).

\section{Discussion}

The mean DDI interval in this study is $145.3 \pm 69.2 \mathrm{~min}$ and is longer than what was observed in similar studies in Benin and Ibadan Nigeria where the mean DDIs were 106 and 119 min respectively $[3,10]$. These centres are old and located in urban communities; health insurance is also available there. However, this DDI was an improvement over what was observed in Enugu and Ife Nigeria where the mean DDIs were 201 and 264 min respectively [2,11]. The apparent improvement may however be due to the fact that these studies were conducted more than 8 years ago and much improvement would have occurred in these centres over the years, moreover the studies with shorter DDI were conducted in 2014 and 2015 respectively. All these DDIs are still far from the recommendation of $30 \mathrm{~min}$. Only $0.86 \%$ of the surgeries were performed within $30 \mathrm{~min}$, which is lower than what was observed by Bello et al. in Ibadan and Chukwudi et al in Benin with a percentage of $2.1 \%$ and $5.7 \%$ respectively. These percentages are still very low $[3,10]$.

Two independent European studies observed a mean DDI of 39.5 and $52.4 \mathrm{~min}$ respectively. The observed difference may be due to improved facilities, better coordination among the surgical team and more importantly is the practice of post service billing and availability of health insurance, which ensures that in the face of emergencies, patients are first attended to and relatives don't have to procure materials before surgery is done $[8,12]$. Health insurance is sadly yet to be available in our centre, which could be because the centre is relatively new and is located in a semi-urban environment.

Lack of funds and non-provision of surgical materials was the leading causes of delay in this study. As post service billing is not available in our centre, patients' relatives usually pay surgical fees and also buy materials before the operation could be performed. This is similar to what was observed by Bello et al due to the unavailability of post service billing, health insurance is also yet to be available to all patients at the centre. Delay in assembly of personnel for surgery and unreadiness of the operating theatre were the major causes of delay that were observed by Onwudiegwu et al. and Onah et al. [2,11]. This could be due to the relatively lower rate of staffing in teaching hospital at the time these studies were conducted. Another important cause of delay was non-availability of blood and blood products this is so because the donors are provided by patients' relatives rather than volunteers [12]. Many of our patients are un-booked and we are unsure of their baseline blood parameters, it is therefore safe in our environment to ensure that blood is made available before commencing surgery especially in patients who are at risk of bleeding. This usually takes some time. This problem was also observed by Bello et al. [10]. These causes of delay are however absent in foreign studies $[8,13,14]$.
There was no statistically significant relationship between measures of foetal outcome and the DDI, which included 5 min APGAR score, SCBU admission, perinatal mortality (P-value 0.11, 0.89, 0.59 respectively). Though contrary to what was observed by Thomas et al. [6] this lack of relationship have been observed repeatedly in previous studies $[2,3,6,11]$. It may therefore suggest that some other factors contribute to perinatal morbidities and mortality following emergency $\mathrm{C} / \mathrm{S}$ which are more important than DDI. Despite the lack of correlation between DDI and perinatal outcome, unnecessary delays are not justified in the face of acute foetal or catastrophic maternal conditions, these conditions include cord prolapse and abruption placenta which had the shortest mean DDI in this study as observed in other studies too $[3,13,15]$. Litigation of Obstetricians should however not be solely on the basis of prolonged DDI in view of its poor relationship with feto-maternal outcomes (Table 7).

\section{Conclusion and Recommendation}

Despite the lack of relationship between DDI and perinatal outcomes, it is important to ensure delivery within short time in emergency $\mathrm{C} / \mathrm{S}$. This could be achieved by ensuring a holistic improvement in health care delivery. Ensuring routine antenatal care for all pregnant women such that most of them are booked, some of the patients presenting as emergency would have been treated as elective cases in which the patient would have had time to prepare for funds and also get her blood donor in the spirit of birth preparedness and complication readiness.

The importance of post service billing and increasing the coverage of the National Health Insurance Scheme (NHIS) cannot be overemphasized. This would ensure that $\mathrm{C} / \mathrm{S}$ is done within the shortest possible time for either the poor or the rich patient in accordance with respectful maternity care.

Encouraging volunteer blood donation and making blood donation a routine for every pregnant woman would ensure that blood is always available in the face of emergencies which can be replaced later when the lives of the mother and fetus have been saved.

\section{References}

1. Kish K, Collea VJ (2013) Operative Delivery. In: Decherney AH, Nathan L, Goodwin MT, Laufer N, (eds) Current Diagnosis and Treatment Obstetrics and Gynecology. Mc Graw Hill, Lange 342-358.

2. Onah HE, Ibeziako N, Umezulike AC, Effetie ER (2005) Decision delivery interval and perinatal outcome in emergency caesarean sections. J Obstet Gynaecol 25: 342-343.

3. Chukwudi OE, Okonkwo CA (2014) Decision - delivery interval and perinatal outcome in emergency caesarean sections at a tertiary institution. Pak J Med Sci 30: 946-950.

4. Pearson GA, MacKenzie IZ (2013) Factors that influence the incisiondelivery interval at caesarean section and the impact on the neonate: A prospective cohort study. Eur J Obstet Gynecol Reprod Biol 169: 197-201.

5. Pearson GA, Kelly B, Russel R, Dutton S, Kurinczuk JJ, MacKenzie IZ (2011) Target decision to delivery intervals for emergency caesarean section based on neonatal outcomes and three-year follow-up. Eur J Obstet Gynecol Reprod Biol 159: 276-281.

6. Thomas J, Paranjothy S, James D (2004) National cross sectional survey to determine whether the decision to delivery interval is critical in emergency caesarean section. BMJ 328: 665.

7. Radhakrishnan G, Yadav G, Vaid NB, Ali H (2013) Factors affecting "decision to delivery interval" in emergency caesarean sections in a tertiary care hospital: a cross sectional observational study. Int J Reprod Contracept Obstet Gynecol 2: 651-656. 
Citation: Owonikoko KM, Olabinjo AO, Bello-Ajao HT, Adeniran MA, Ajibola TA (2018) Determinants of Decision to Delivery Interval (DDI) in Emergency Caesarean Sections in Ladoke Akintola University of Technology Teaching Hospital Ogbomoso, Nigeria. Clinics Mother Child Health 15: 294. doi:10.4172/2090-7214.1000294

Page 5 of 5

8. Cerbinskaite A, Malone S, McDermott J, Loughney AD (2011) Emergency Caesarean Section: Influences on the Decision-to-Delivery Interval. Hindawi Publishing Corporation. Preg 15: 123-128.

9. American College of Obstetricians and Gynecologists Committee on Patient Safety and Quality Improvement (2011) ACOG Committee Opinion No 487: Preparing for clinical emergencies in obstetrics and gynecology. Obstet Gynecol 117:1032-1024.

10. Bello FA, Taiwo AT, Oluwasola TO (2015) Decision to delivery intervals and perinatal outcomes following emergency caesarean deliveries in Nigerian tertiary hospital. Int J Obstet Gynecol 279-283.

11. Onwudiegwu U, Makinde ON, Ezechi OC, Adeyemi A (1999) DecisionCaesarean delivery interval in a Nigerian university hospital; implications for maternal morbidity and mortality. J Obstet Gynecol 19: 30-33.
12. Bates L, Hassall O (2010) Should we neglect or nurture replacement blood donors in sub-Saharan Africa? Biologicals 38: 65-67.

13. Kolas T, Hofos D, Olan P (2006) Predictions for the decision-to-delivery interval for emergency Caesarean section in Norway. Acta Obstetricia et Gynecologica 85: 561-566.

14. Tuffnell DJ, Wilkinson K, Beresford N (2001) Interval between decision and delivery by caesarean section-s are current standards available? Observational case series. BMJ 322: 1330-1333.

15. Sayegh I, Dupuis O, Clement HJ, Rudigoz RC (2004) Evaluating the decision to delivery in emergency caesarean sections. Euro J Obstet Gynaecol Reprod Biol 116: 28-33. 